\title{
Ambivalent property of bilirubin in human bile juice
}

\author{
Anna Blázovics, Péter Sípos, Ferenc Örsi,* Mervat Abdel Rahman** \\ Semmelweis University, Budapest, Hungary, *Technical University of Budapest, \\ Hungary, ** Student Hospital, Cairo University, , Giza
}

\begin{abstract}
Gallstones are formed as a result of many metabolic disorders e.g. chronic haemolytic anaemia, diabetes mellitus, ileal diseases, short bowel syndrome, gluten sensitive enteropathy, elevated serum lipids or Crohn's disease. The relationship between gallstone disease and free radical reactions is not known exactly even today. Free radicals are involved in many clinical conditions e.g. in hyperlipidemia and in fatty liver. Oxygen free radicals are produced and accumulated while the function of mitochondrial and microsomal electron transport or in peroxisomes and the activated arachidonic acid cascade. Spontaneous lipid peroxidation and oxygen free radical products of respiratory burst of Kupffer cells can be added to peroxide pool of liver tissue. Tissues, cells and subcellular particles exhibit different specific defence activities in pathological processes, which involve free radicals.

The activity of microsomal P450 enzyme system and the microsomal structure are changed during pathological free radical attack and the cholesterol/bile acid ratio in bile juice is also altered. At the same time bilirubin metabolism can also be modified.

Bile samples of 88 cholecystectomysed patients in both sexes (male: 29, female: 59) were examined. HPLC analysis (HP1090 liquid chromatograph with diode array detector) was used for the detection of free bilirubin and bilirubin derivates. HP5890 gas chromatograph and flame ionization detector was used for fatty acid analysis. The induced chemiluminescence intensity was also determined in bile juice with (Berthold Lumat 9501) luminometer.

As results show, the occurrence of $\mathrm{C} 18: 1 \varpi 9, \mathrm{C} 18: 2 \varpi 6, \mathrm{C} 20: 4 \varpi 6$ fatty acids were in high percentage in gallbladder bile in every case of randomly chosen 17 cholecystectomysed patients in both sexes suffered from cholecystitis chronica with gallstone. Lipid peroxidation products (diene conjugates and malondialdehyde) were detected in all cases of bile as well. Mathematical statistical analysis showed, that positive significant correlation was between low concentration of total bilirubin of gallbladder bile and chemiluminescent intensity in hydrogen peroxide luminol system. Extra high chemiluminescence light could be detected in bile samples of patients with severe clinical state. Bilirubin pro-and antioxidant forms are justified in human gallbladder bile.
\end{abstract}

Key words: bilirubin, human bile, gallbladder, gallstones, free radicals.

\section{Introduction}

Due to deranged liver structure and function both mechanism of biliary passage and composition of bile juice are changed significantly (Cohen and Soloway 1985, Abdel Rahman 1995, 1996, Sipos 2001, Bosma et al., 2003).)

Cholesterol supersaturation, gallbaldder hypomotility and mucin hypersecretion are essential for the formation of cholesterol gallstones. Exogen arachidonic-lecithin stimulates the formation of gel matrix lining the gallbladder wall and accelerates the nucleation process (Levy et al., 1984, Cohen et al.,1985 Carey 1988, Trotman 1982). Supersaturation of bile with calcium hydrogen bilirubinate is essential for pigment gallstone formation. The gallbladder bile in brown or black pigment gallstone diseases is usually not saturated with cholesterol and contains an increased proportion of mono-and unconjugated bilirubin IX. $\alpha$. Bilirubin hypersecretion can be observed in haemolytic disorders or enterohepatic cycling in nonhaemolytic 
states (Trotman 1985, Nakao et al., 1988). Bacterial infection of bile in brown pigment stone approaches $100 \%$. Bacterial $\beta$ glucuronidases hydrolyse the conjugated bilirubin (Trotman 1982, Vitetta and Sali 1992). Bilirubin is the endproduct of hem catabolism, (formed in reticuloendothelial cells) coming from haemoglobin, myoglobin and many respiratory enzymes. The aim of this research is to study the role of bilirubin and free radicals- mediated mechanisms in gallstone formation.

\section{Subjects and Methods}

Bilirubin standard was purchased from SIGMA Aldrich Kft, HPLC grade chloroform and ethanol were obtained from MERCK, acetic acid (99-100\%) and all other reagents were analytical quality from REANAL, Budapest.

Bile samples of 88 cholecystectomysed patients ( aged between 40-60 years ) in both sexes (male: 29, female: 59) were examined. All patients suffered from cholecystitis chronica. The stones were of mixed types.

Bile samples of randomly chosen 17 cholecystectomysed patients in both sexes (male: 4, female: 13) were examined with HPLC and GC.

HP 5890 gas chromatograph with flame ionization detector and split capillary injector was used for fatty acid analysis of bile. Labinform A/D converter and data station was employed to collect the data and processed the chromatograms. Colonna: Carbovax $20 \mathrm{M}(25 \mathrm{~m}$ x $0.2 \mathrm{~mm}, 0.25 \mu \mathrm{m}$ film thickness), column oven: $180{ }^{\circ} \mathrm{C}$, injector $280{ }^{\circ} \mathrm{C}$, detector $205{ }^{\circ} \mathrm{C}$, injector: split split ratio: 1:50, carrier gas: nitrogen $0.3 \mathrm{~cm}^{3} / \mathrm{min}$, detector gas: hydrogen 30.0 $\mathrm{cm}^{3} / \mathrm{min}$, air: $400 \mathrm{~cm}^{3} / \mathrm{min}$, nitrogen: 30 $\mathrm{cm}^{3} / \mathrm{min}$. The sample injections were $10 \mu \mathrm{l}$ in hexane. The peaks were identified by comparison with retention behaviour of known standards of FAME mixtures (Alexander, 1985).

Diene conjugates were measured by the recommendation of AOAC method (1984) with isooctane fractionated extraction. Volume of bile samples was 500 $\mu \mathrm{l}$ in each measurement.
The TBA reactive products (malondialdehyde /MDA/) were monitored by the thiobarbituric acid test of Pyles et al., 1993. We controlled the bilirubin TBA reaction. The find equation, to be used to correct for absorbance due to interfering substances in measuring the MDA-TBA chromogen is as follow: $\mathrm{MDA}_{532}=1 . .22$ $\left(\left(\mathrm{A}_{532}\right)-(0.56)\left(\mathrm{A}_{510}\right)+(0.44)\left(\mathrm{A}_{560}\right)\right)$

A recently developed chemiluminescence assay adapted to a Berthold Lumat 9501 instrument was applied for determination of the total scavenger capacity or free radical activity of the bile (Blázovics et al., 1999).

Raw data operation mode was used. The built-in microprocessor performed the data processing and printed out the final results in relative light unit (RLU). Procedure: The first trigger solution of $\mathrm{H}_{2} \mathrm{O}_{2}\left(0.30 \mathrm{ml}, 10^{4}\right.$ dilution $)$, the second trigger solution of microperoxidase $(0.30$ $\mathrm{ml}, 1 \mathrm{mmol} / \mathrm{l}$ ) as a catalyst. Light emission is initiated by addition of the alkaline luminol solution $(\mathrm{pH} 9.8$ ) (in $0.050 \mathrm{ml}$ of $\left.7 \times 10^{-5} \mathrm{~mol} / \mathrm{l}\right)$. Photon output is accumulated for $30 \mathrm{sec}$. The volumes of bile samples were $0.5 \mathrm{ml}$ respectively. Luminol solution was added to the bile samples and was mixed with a vortex $(10 \mathrm{sec})$ before fixing the tube in a holder. Each measuring point represents five parallel data in luminoldependent chemiluminescence experiments when $\mathrm{cv} \%$ was $<5 \%$. ( Watanabe et al., 1992)

Free bilirubin was determined from chloroform extraction with Muraca method (1983). The bilirubin and bilirubin derivates of collected bile samples were analysed by HP 1090 M liquid chromatograph with diode-array detector. Colonna CHROSIL $10 \mu \mathrm{m}, 250 \times 4,6 \mathrm{~mm}$, eluent: chloroformethanol 99:1 $+0,5 \%$ acetic acid, separation: isocratic, flow: $1 \mathrm{~cm}^{3} /$ perc, detection: $440 \mathrm{~nm}$, temperature: $40{ }^{\circ} \mathrm{C}$.

\section{Results and Discussion}

In vitro studies strenghtened, that free radicals influence the gallstone formation (Eder et al.,1996). In animal experiments free radical reactions were observed in the 
flow bile as well as gallbladder bile (Blázovics et al.,1996, 1997; Sipos 2003). Occurrences of $\mathrm{C} 18: 1 \omega 9, \mathrm{C} 18: 2 \omega 6$ and C20:4 66 fatty acids were present in high percentages in the gallbladder biles of the examined cholecystectomysed patients. In every case the patients suffered from cholecystitis chronica with gallstones (Table 1.).

Unsaturated fatty acids are precursor molecules for diene conjugates. There was no significant correlation between diene conjugates and total bilirubin in human gallbladder bile (Figure 1.) It was not surprising, since diene conjugates are transient lipid peroxidation forms. It was also interesting, that high diene conjugate concentration could be detected in high bilirubin concentration too Figure 2. shows the correlation between MDA, the end-product of lipid peroxidation process and total bilirubin concentration.

Both antioxidant and free radical formation of bilirubin (concentration dependently) can be present in the gallbladder and in enterohepatic circulation of the bile. Figure 3. shows the ambivalent property of bilirubin molecule in human gallbladder bile. Bilirubin is a free radical in low concentration range $100-800 \mu \mathrm{mol} / \mathrm{l}$, and antioxidant in higher concentrations in the bile.

It can be supposed, that oxygen free radicals and bilirubin reactions contribute the bile lipid peroxidation pool and gallstone formation, thus, not only biological, biochemical but physicoch-emical factors may play an important role in the formation of gallstones.

Free bilirubin and two oxidable derivates can be seen in Figure 4. The basic structure of bilirubin has six intracellular stable hydrogen bonds, whereby the bilirubin is insoluble in aqueous phase. Solubility of bilirubin in acids and alkalies is better, than in normal pH (Bonnett 1976). The potentially cytotoxic lipid soluble bilirubin is transported in the plasma tightly bond to albumin. Conjugated bilirubins (bilirubin esters) are formed from bilirubin and glucuronic acid by microsomal enzymes of liver. Sulphate, xylose and glucose conjugation also occur to a small extent and may be increased in cholestasis
(Chowdhury 1983). In general the small rate transport of free bilirubin molecules from the microsomes can be observed parallel with conjugated bilirubins (Nakao et al.,1988, Okta et al.,1992).

The bilirubin content of the human gallbladder bile is cc. $5 \mathrm{mmol} / \mathrm{l}$. Bilirubin can be found in mono-and diglucuronide forms, but free bilirubin molecules can be detected in the gallbaldder bile as well. Sources of free bilirubin molecules are in the microsomal P450 system in the liver and bacterial enzymatic transformation in gastrointestinal tract. Bilirubin reduced forms: urobilinogen, urobilin and stercobilin absorb in the terminal ileum and in large intestine (Chowdhury and chowdhurg 1983, Bosma et al.,2003).

In this study, diene conjugates and malondialdehyde were detected in gallbladder bile after cholecystectomy. Free bilirubin and bilirubin derivatives and fatty acids were also detected in randomly chosen bile samples. Bilirubin pro-and antioxidant forms are justified in human gallbladder bile.

Positive correlation is found in the literature between bacterial $\beta$-glucuronidase activity and the proportion of unconjugated bilirubin in bile ( Vitetta and Sali 1992). In cholangitis, $\mathrm{pH}$ of bile becomes lower toward the optimal $\mathrm{pH}$ of bacterial $\beta$ glucuronidase activity. Papillary dysplasia and or severe dysplasia of the bile duct epithelium may be caused by aerobic and anaerobic bacterial infection of the biliary tract in contribution with bile stasis. Appearance of Escherichia coli and Clostridium. perfringens $\beta$-glucuronidase activity in bile duct is a key factor in primary bile stone formation (Nakao, et al 1988, Okta et al.,1992). Free bilirubin interferes with free fatty acid metabolism in pathological conditions (Bayes Garcia et al.,1989). Unsaturated fatty acids in food seem to increase the risk of gallstone formation (Cohen, 1985). Ultraweak chemiluminesc-ence from bilirubin occurs in the presence of triplet oxygen and it can be stimulated by aldehydes (Watanabe 1992). Bilirubin is a known photodyinamic agent producing $\mathrm{O}_{2}$ in tbe presence of $\mathrm{O}_{2}$ 
and light (Yang 1992). Free radical forms of bilirubin are justified by ESR technique (Shen et al., 1996). The kinetic curve of the regeneration of bilirubin radicals has been determined and the reaction follows a zero order mechanism (Yang et al., 1992). Linear correlation was found between the amplitude of the free radical signal of the electron spin resonance spectrum of paraffin embedded liver blocks and the number of bile casts in the histological section made from the same blocks. ESR signal intensity also correlated linearly with the content of calcium bilirubinate in pigment gallstone samples (Shen et al., 1996).
At the same time antioxidant properties of conjugated bilirubin and biliverdin have been discussed in several studies. In vivo, the plasma antioxidant capacity of jaundiced newborn infants is related to the level of bilirubin (Belanger et al., 1997).

Conjugated bilirubin at low micromolar concentrations inhibits luminol chemiluminescence response of stimulated human polymorphonuclear leucocytes. Bilirubin can scavenge peroxyl radical. Furthermore under $2 \%$ of oxygen in liposomes bilirubin suppresses the oxidation more than $\alpha$ tocopherol (Stocker et al. 1987,Stocker and Peterhans 1989).

Table 1.

Figure 1.

\begin{tabular}{|c|c|c|}
\hline \multicolumn{3}{|c|}{$\begin{array}{l}\text { Fatty acid composition in human } \\
\text { gallbladder bile with cholecystitis chronica }\end{array}$} \\
\hline \multicolumn{2}{|c|}{ Fatty acids } & Gallbladder bile \\
\hline C14:0 & miristic acid & $1,79 \pm 0,64$ \\
\hline C16:0 & palmitic acid & $15,90 \pm 1,46$ \\
\hline \begin{tabular}{|l|} 
C16:1 \\
\end{tabular} & palmitoyl acid & $10,54 \pm 1,56$ \\
\hline C18:0 & stearic acid & $7,38 \pm 1,18$ \\
\hline C18:1 & oleic acid & $28,05 \pm 2,19$ \\
\hline C18:2 & linoleic acid & $28,05 \pm 1,15$ \\
\hline C20:0 & arachin acid & $2,51 \pm 0,80$ \\
\hline \begin{tabular}{|l|} 
C20:4 \\
\end{tabular} & arachidonic acid & $6,07 \pm 0,89$ \\
\hline
\end{tabular}

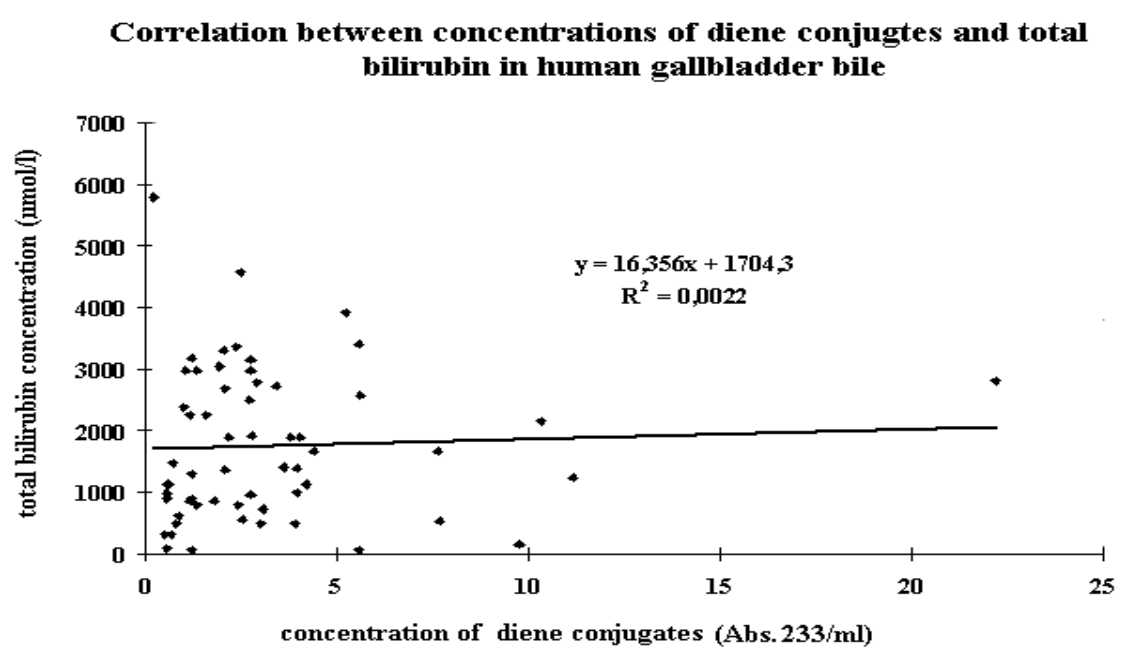


Figure 2.

Correlation between concentration of $\mathrm{MDA}$ and total bilirubin in human gallbladder bile

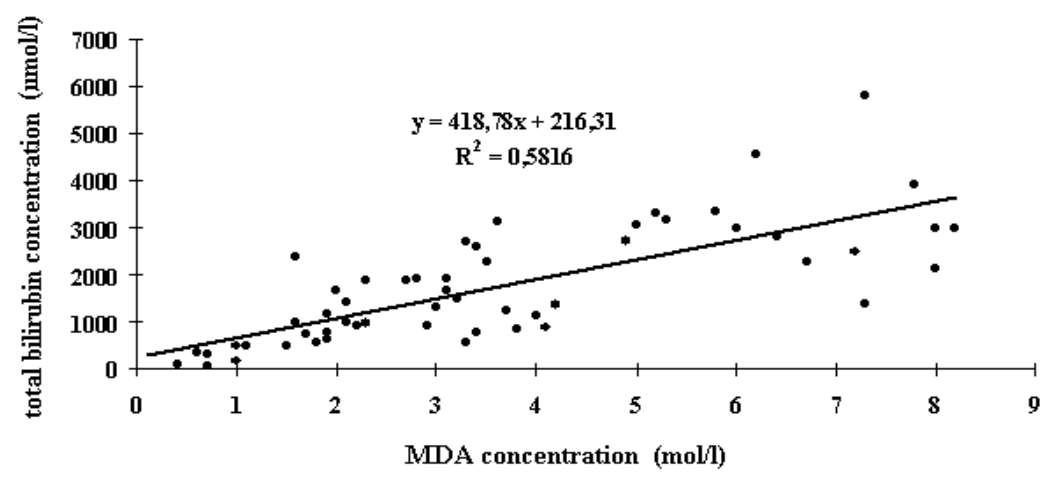

Figure 3.

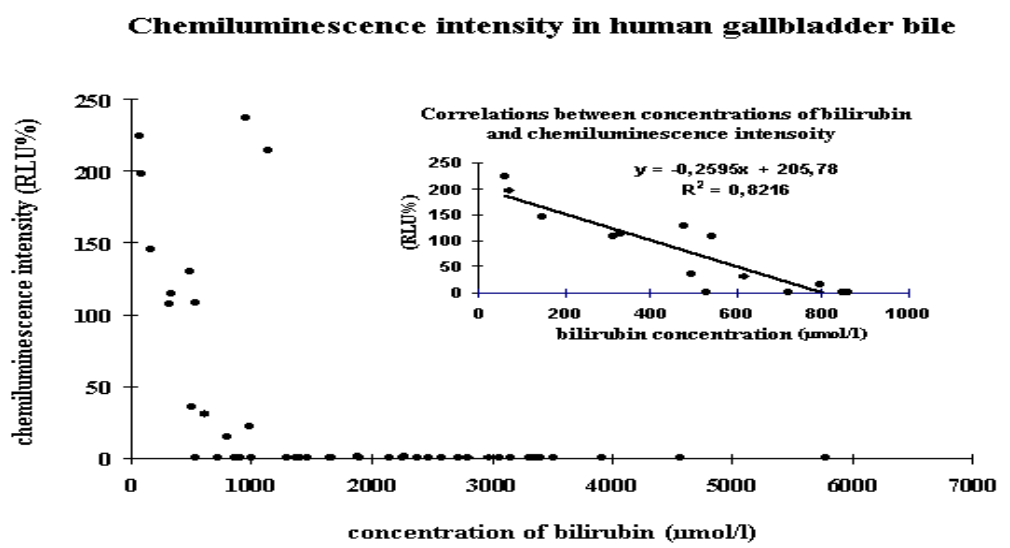

Figure 4.

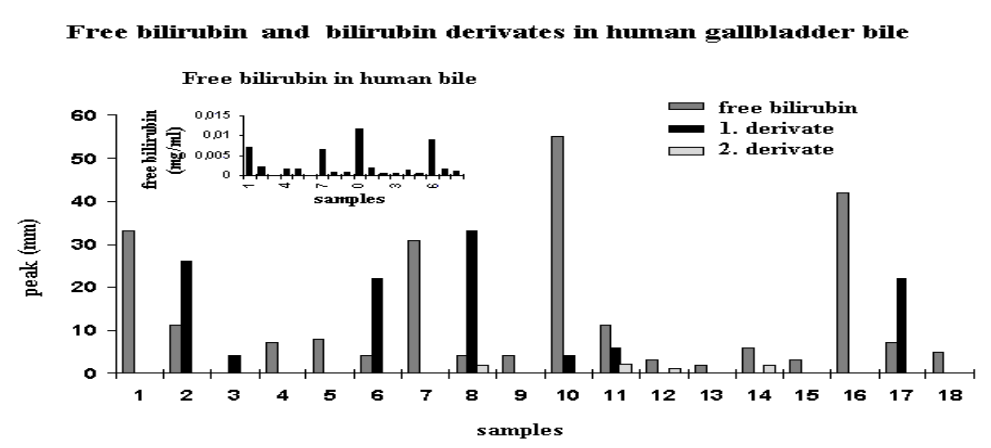

\section{Acknowledgements}

Authors express their thanks to Ms. Edina Pintér and Ms. Sarolta Bárkovits for their excellent technical assistance. This study was supported by ETT 02/517 and ETT 002/2003

\section{References}

1. Abdel Rachman M.( 1996) : Free radical reactions in bile secretion and gallstone disease, 1996, Ph.D Thesis, Semmelweis University, Hungary

2. Abdel Rahman M, Blázovics A, Ágoston M, Asztalos I, Prechl J, Vallent K, Fehér J (1995) : A chemiluminescent study for detection of free radicals in gallbladder bile in gallstone diseases, Ces. a Slov Gastroent., 1995, 49, 7-13. 
3. Alexander LR, Justice JB (1985) : Fatty acid composition of human erythrocyte membranes by capillary gas chromatogr-aphy mass spectrometry, J. Chromatogr., 1985, 342, 1-12.

4. AOAC (1984): Official Methods of Analy-sis 28054 B. 14th ed.Arlington USA, 1984.

5. Bayes Garsia R, Maldonado Sorano J, Molina Font JA ( 1989) : Interrelation of bilirubin and free fatty acids in newborn infants with pathologic conditions, An. Exp. Pediatr., 1989, 30, 27-31.

6. Belanger S, Lavoie JC, Chessex $\mathbf{P}$ (1997): Influence of bilirubin on the antioxidant capacity of plasma in newborn infants, Biol. Neonate, 1997, 71, 4, 233-238.

7. Blázovics A, Fehér E, Abdel Rahman M, Prechl J, Ágoston M, Fehér J (1996): Free radical in connection of bile and liver, Ces. a Slov. Gastoent., 1996, 50, 73-78.

8. Blázovics A, Örsi F, Kemény $\mathbf{T}$, Fehér E, Barta I, Fehér J (1997): Lipids and lipid peroxidation in connection of bile and liver, Progr. HepatoPharmacol., 1997, 2, 103-117.

9. Blázovics A, Kovács Á, Lugasi A, Hagymási K, Bíró L, Fehér J (1999): Antioxidant defence in erythrocytes and plasma of patients with active and quiescent Crohn's disease and ulcerative colitis: A chemiluminescent study, Clin. Chem., 1999, 45, 6,895-896

10. Bonnett R, Davies JE, Hursthouse MB (1976): Structure of bilirubin, Nature, 1976, 262, 326-327.

11. Bosma P. Inherited disorders of bilirubin metabolism (2003): a review, J. Hepatol., 2003, 38, 107-117.

12. Carey MC(1988): Formation of pigment gallstones. In: Paumgartner G, Stiehl A and Gerock W (ed) Trends in bile acid research, Dordrecht. 1988, 259281.

13. Chowdhury JR, Chowdhury NR (1983): Conjugation and excretion of bilirubin, Semin. Liv. Dis. 1983, 3, 11-15.

14. Cohen S, Soloway RD (1985): Gallstones, Churchill Livingstone, New York 1985.

15. Eder IM, Miquel JF, Jüngst D, Paumgartner G, von Ritter C ( 1996): Reactive oxygen metabolites promote cholesterol crystal formation in model bile: role of lipid peroxidation, Free Rad. Biol. Med., 1996, 20, 743749.

16. Levy PF, Smith BF, LaMont JT (1984): Human gallbladder mucin accelerates nucleation of cholesterol in artificial bile, Gastroenterol., 1984, 87, 270275.

17. Muraca M, Blanckaert N (1983): Liquid-chromatographyc assay and identification of mono-and diester conjugates of biliru-bin in normal serum, Clin. Chem., 1983, 29, 1767-1771.

18. Nakao T, Tabata $M$, Nakayama $F$ (1988): Unconjugated bilirubin in hepatic bile with brown pigment gallstone and cholangitis, Dig. Dis. Sci., 1988, 33, 1116-1120.

19. Okta T, Nagakawa T, Tsukioka Y, Sanada H, Miyazaki I, Terada T (1992): Proliferative activity of bile duct epithelium after bacterial infection in dogs, Scand J. Gastroenterol., 1992, 27, 845-851.

20. Pyles IA, Strejskal J, Eizing S (1993): Spectrophotometric measurement of plasma 2thiobarbituric acid-reactive substances in the presence of hemoglobin and bilirubin interference, (4355) Proc. Soc. Exp. Biol. Med., 1993, 4, 407419.

21. Shen T, Lin C, Yang Z, Weng $\mathbf{S}$, Lu J, Shen G, Gu Y, Xu Z, Fu $\mathrm{X}$, Wang $\mathrm{K}$, Wu J, Zhou $\mathrm{X}$ (1996): Presence of free radicals in pigment gallstone in vivo, Chin. Med. J. Engl., 1996, 109, 6, 446-449.

22.Sípos P (2001): Free radical reactions in the bile. Doctor of Philosophy, 2001, Semmelweis University, Hungary, 
23. Sipos P, Szentmihályi K, Fehér E, Abaza M, Szilágyi M, Blázovics A (2003): Some effects of lead contamination on liver and gallbladder bile, Acta Biol. Szegediensis, 2003, 47, 1-4, 139142.

24. Stocker R, Peterhans E (1989): Antio-xidant properties of conjugated bilirubin and biliverdin biologically relevant scave-nging of hypochlorous acid. Free. Rad. Res. Com., 1989, 6, 57-66.

25.Stocker R, Yamamoto Y, McDonagh AF, Glazer AN, Ames BN (1987): Bilirubin is an antioxidant of possible physiological importance, Science, 1987,235,1043-1046.
26. Trotman BW (1992): Formation of pigment gallstones, In: Cohen $S$ and Soloway RD (ed) Gallstones, New York. 1985, 299300.

27. Vitetta L, Sali A (1992): Primary bile duct stones and bacterial activity HPD. Surg. 1992, 6, 23 32.

28. Watanabe H, Usa M, Kobayashi M, Agatsuma S, Inaba $\mathbf{H}$ (1992): Weak chemiluminescence of bilirubin and its stimulation by aldehydes, J. Biolum. Chemilum., 1992, 7:1-11.

29. Yang ZH, Wang K, Liu XT (1992): studies of electron spin resonance on bilirubin free radicals, Sci. China B., 1992, 35, 1093-1100.

\section{الخاصية المزدوجة للبليروبن في السائل المراري للإنسان}

$$
\begin{aligned}
& \text { أنا بلازوفيتش* ، بيتز شيبوش ، فرنس أورشى *** ، ميرفت عبد الرحمن**** دانش }
\end{aligned}
$$

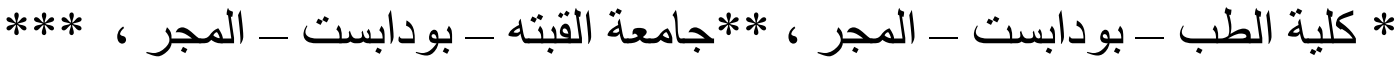

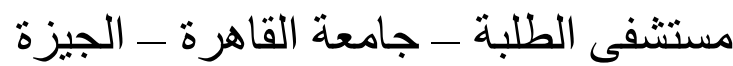

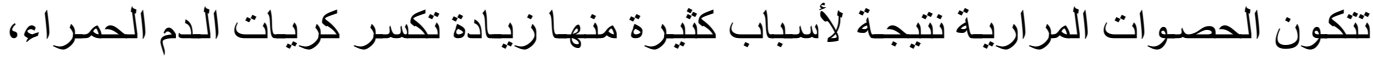

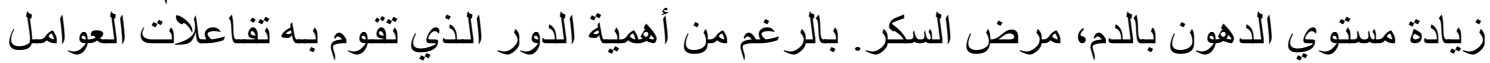

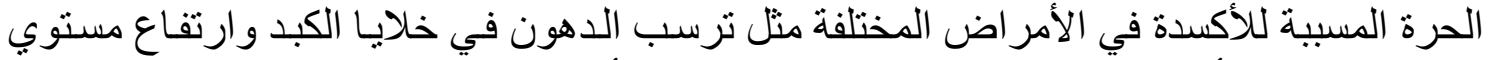

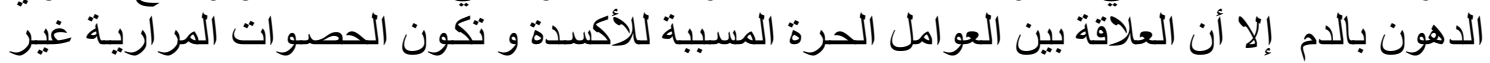

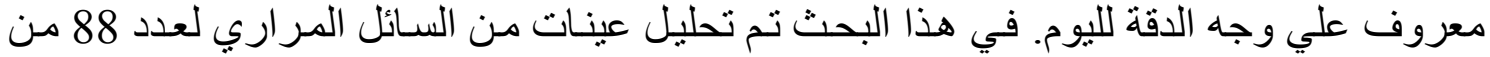

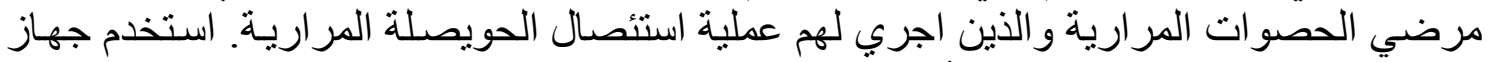

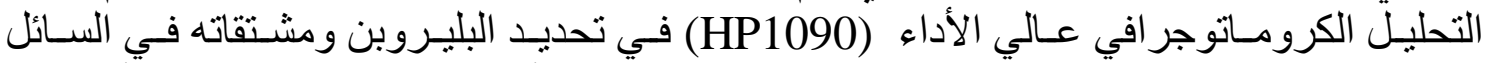

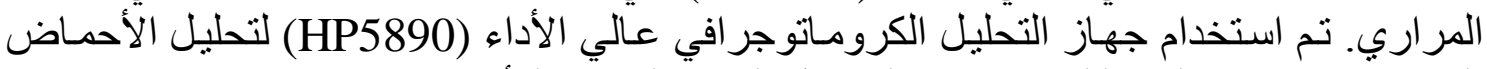

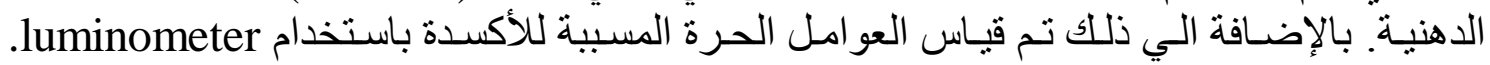
أوضحت النتائج وجود الأحماض الدهنية C18:1

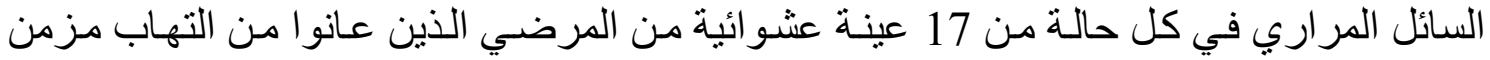

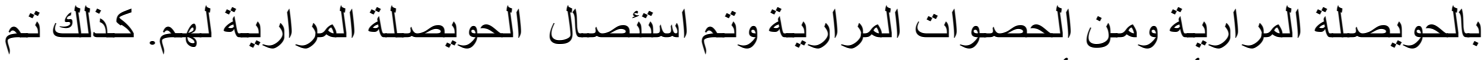

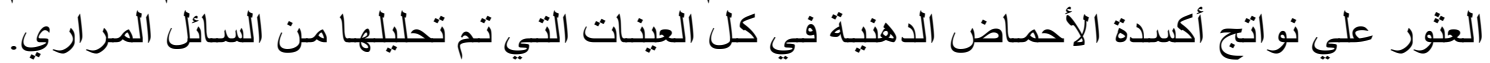

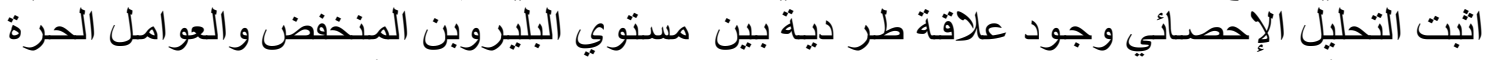

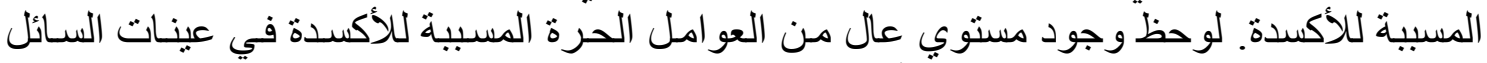

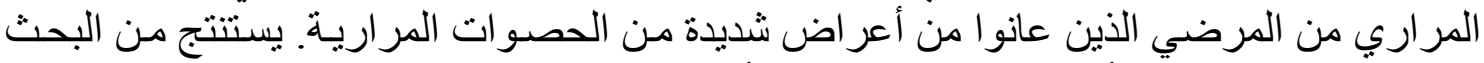

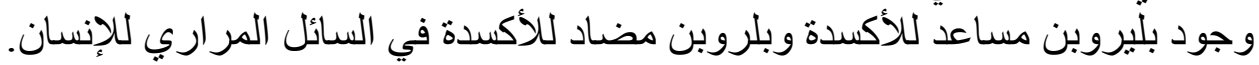

